\title{
Influência dos fatores ambientais no uso de máscaras não profissionais utilizadas na prevenção da transmissão da Covid-19
}

\section{Influence of environmental factors on the use of face masks in the prevention of the transmission of Covid-19}

Dayane Otero Rodrigues ${ }^{1}$, Leonardo Morato Duarte ${ }^{2}$

\section{RESUMO}

O artigo objetivou analisar a relação da umidade relativa (UR) do ar e o uso de máscaras não profissionais utilizadas na pandemia da Covid-19. Realizou-se um experimento de pesagem de dois modelos de máscaras não profissionais ao início e a cada 15 minutos de seu uso durante 3 a 5 horas em diferentes condições de UR do ar. Os valores atingidos de massa com a máscara de algodão em 3 horas de uso no ambiente aberto ( $30 \%$ de UR) foram atingidos em 15 minutos no fechado com $50 \%$ de UR e foram extrapolados em 3 vezes em 15 minutos no com $70 \%$ de UR e em 4 vezes no com $90 \%$ de UR. Os valores atingidos de massa com a máscara de algodão e elastano em 3 horas de uso no ambiente aberto foram atingidos também em 3 horas no fechado com $50 \%$ de UR, foram extrapolados em apenas 15 minutos no com $70 \%$ de UR, e em 3 vezes no com $90 \%$ de UR. Os fatores ambientais como a UR do ar alta podem diminuir o tempo de 3 horas de uso, recomendado pela Anvisa, para máscaras não profissionais, sugerindo a necessidade de maior discussão pelos órgãos de saúde.

Palavras-chave: Covid-19. Máscaras faciais. Umidade. Prevenção.

\section{ABSTRACT}

The article aimed to analyze the relationship between the relative humidity $(\mathrm{RH})$ of the air and the use of non-professional masks used in the Covid-19 pandemic. A weighing experiment was carried out on two models of non-professional masks at the beginning and every 15 minutes of their use for 3 to 5 hours in different $\mathrm{RH}$ air conditions. The achieved values of mass with the cotton mask in 3 hours of use in the open environment $(30 \% \mathrm{RH})$ were reached in 15 minutes in the closed with $50 \% \mathrm{RH}$ and were extrapolated 3 times in 15 minutes in the $70 \% \mathrm{RH}$ UR and 4 times at $90 \% \mathrm{RH}$. The achieved values of mass with the cotton and elastane mask in 3 hours of use in the open environment were also reached in 3 hours in the closed with $50 \% \mathrm{RH}$, were extrapolated in just 15 minutes in the one with $70 \% \mathrm{RH}$, and in 3 times not at $90 \% \mathrm{RH}$. Environmental factors such as high air RH can decrease the time of 3 hours of use, recommended by Anvisa, for non-professional masks, suggesting the need for further discussion by health agencies.

Keywords: Covid-19. Face masks. Humidity. Prevention.
Doutorado em Imunologia e Parasitologia aplicadas, Docente do Centro das Ciências Biológicas e da Saúde, Universidade Federal do Oeste da Bahia, UFOB.

E-mail: dayotero@yahoo.com.br

Doutorado em Geologia, Docente do Centro das Ciências Exatas e das Tecnologias, Universidade Federal do Oeste da Bahia, UFOB. 


\section{INTRODUÇAOO}

O vírus denominado síndrome respiratória aguda grave coronavírus-2 (SARS-CoV-2) foi primeiramente detectado em dezembro de 2019 em Wuhan, China (CANDIDO et al., 2020; WORLDOMETERS, 2020; LAI et al., 2020; WORLD HEALTH ORGANIZATION, 2020a; BOCCIA, RICCIARD, IOANNIDIS, 2020). É um vírus de ácido ribonucléico (RNA), envelopado, pertence ao gênero Betacoronavirus e família Coronaviridae (CORONAVIRIDAE STUDY GROUP, 2020). O SARS-CoV-2 está intimamente relacionado geneticamente aos coronavírus semelhantes ao SARS derivados de morcegos (LU et al., 2020). A transmissão humana ocorre principalmente por meio de gotículas respiratórias e contato direto, semelhante aos vírus da gripe humana e SARSCoV (GUAN et al., 2020). Recentemente foi descrita a contaminação aérea por aerossóis suspensos no ar pela comunidade científica, a exemplo de Morawska e Milton (2020); Buonanno, Morawska e Stabile (2020); Cai e colaboradores (2020); Li e colaboradores (2020) e pelos órgãos de saúde como National Health Commission of the People's Republic of China e Centers for Diseases Control and Prevention (CDC) (NGONGHALA et al., 2020; WANG, DU, 2020; FENG et al., 2020).

SARS-CoV-2 causa uma infecção respiratória aguda em humanos, nomeada Corona-Virus Disease-2019 (COVID-19) pela Organização Mundial de Saúde (OMS) (WORLD HEALTH ORGANIZATION, 2020a). E foi declarado o surto como uma emergência de saúde pública pela OMS em 30 de janeiro de 2020 (SOUZA et al., 2020). A Covid-19 propagou-se rapidamente, sendo que se tornou uma pandemia em pouco mais de dois meses, apresentando taxas mundiais altas de contaminação (68.845.368) e mortalidade (1.570.304) segundo a OMS (WORLD HEALTH ORGANIZATION, 2020b; WORLDOMETERS, 2020). A doença pode apresentar sintomas clínicos relatados comumente como febre, tosse seca, fadiga, dispneia, anosmia, ageusia ou alguma combinação desses (GUAN et al., 2020; SOUZA et al., 2020). A OMS aponta outros sintomas que são menos comuns e podem afetar alguns pacientes como congestão nasal, dor de cabeça, conjuntivite, dor de garganta, diarreia, erupção na pele ou descoloração dos dedos das mãos ou dos pés (WORLD HEALTH ORGANIZATION, 2020c).

A elevada infectividade de seu agente etiológico, o coronavírus SARS-CoV-2, aliada à ausência de imunidade prévia na população humana e à inexistência de vacina, fez com 
que o crescimento do número de casos fosse exponencial, sendo necessária a adoção de medidas para tentar prevenir sua transmissão (KUCHARSKI et al., 2020).

Nesse contexto, as intervenções não farmacológicas (INF) são indicadas pela OMS e comunidade científica, incluindo medidas com alcance individual, ambiental e comunitário, como a lavagem das mãos, a etiqueta respiratória, o distanciamento social, o arejamento e a exposição solar de ambientes, a limpeza de objetos e superfícies, e a restrição ou proibição ao funcionamento de escolas, universidades, locais de convívio comunitário, e locais onde há aglomeração de pessoas, além do uso de máscaras não profissionais, que atuam como barreiras físicas, diminuindo a exposição e o risco de infecção para a população em geral (WORLD HEALTH ORGANIZATION, 2020 d; LYU, WEHBY, 2020; AGÊNCIA NACIONAL DE VIGILÂNCIA SANITÁRIA, 2020).

Houveram divergências quanto ao uso generalizado de máscaras não profissionais no início da pandemia, a exemplo das autoridades em saúde pública dos Estados Unidos Americanos (LYU, WEHBY, 2020). Entretanto, atualmente é comprovado que o uso de máscaras não profissionais é uma medida que diminui a possibilidade de transmissão do SARS-CoV-2, sendo recomendado seu uso pelos órgãos mundiais de saúde como OMS, CENTERS FOR DISEASE CONTROL AND PREVENTION (CDC), Agência Nacional de Vigilância Sanitária (Anvisa) e comunidade científica (WORLD HEALTH ORGANIZATION, 2020d; CENTERS FOR DISEASE CONTROL AND PREVENTION, 2020; AGÊNCIA NACIONAL DE VIGILÂNCIA SANITÁRIA, 2020). No Brasil foi publicada em 2 de julho de 2020 a lei nacional de obrigatoriedade do uso de máscaras de proteção individual para circulação em espaços públicos e privados acessíveis ao público, em vias públicas e em transportes públicos (BRASIL, 2020).

No sentido de promover e apoiar as ações para a saúde pública, a Anvisa elaborou um manual de orientação à produção de máscaras não profissionais e indica a utilização preferencialmente de tecidos que contenham algodão em sua composição, bem como tecidos sintéticos apropriados, desde que o fabricante garantisse que 0 tecido não causasse alergia, e fosse adequado para uso humano. O manual destaca que para fins de ampliar o acesso, é importante que a máscara tenha custo baixo. E recomenda que o produto manufaturado tenha 3 camadas: uma camada de tecido não impermeável na parte frontal, tecido respirável no meio e um tecido de algodão na parte em contato com a superfície do rosto (AGÊNCIA NACIONAL DE VIGILÂNCIA SANITÁRIA, 2020).

No referido manual, acompanhando as recomendações de produção das máscaras estão algumas diretrizes quanto ao seu emprego, como evitar o uso das máscaras não 
profissionais por tempo prolongado (limitado em até três horas) e/ou quando úmidas, pois a eficácia de filtragem fica comprometida e amplia o risco de contaminação por microrganismos (AGÊNCIA NACIONAL DE VIGILÂNCIA SANITÁRIA, 2020). Entretanto, o manual negligencia a influência dos fatores ambientais como a umidade relativa (UR) do ar no uso das máscaras, de onde inferimos que pode ocorrer uma diminuição do tempo de uso recomendado quando utilizadas em ambientes com UR do ar alta, como nas regiões Sul, Sudeste, Norte e litoral do Nordeste, que são áreas úmidas na maior parte do ano. Esta questão requer um olhar mais crítico quanto ao uso das máscaras não profissionais pela população durante a pandemia da Covid-19 nestes locais.

A comunidade científica está unindo forças e realizando muitas investigações com publicações nacionais e internacionais à fim de produzir conhecimento sobre esta nova virose, no que tange seus aspectos epidemiológicos clássicos e moleculares, patogênicos e biológicos, imunológicos e preventivos, incluindo o uso de máscaras não profissionais (SOUZA et al., 2020; MOUSAVIZADEH, GHASEMI, 2020; LYU, WEHBY, 2020; FISCHER et al., 2020). No sentido de contribuir com a ciência, torna-se pertinente a realização de estudos que busquem produzir subsídios para a prevenção da COVID-19, sendo assim, este estudo objetivou analisar a influência dos fatores ambientais como a UR do ar no uso de máscaras não profissionais utilizadas na pandemia da Covid-19.

\section{MATERIAIS E METODOS}

Foi realizado um estudo do tipo experimental, laboratorial, buscando responder à pergunta problema motivadora desta investigação: a umidade relativa do ar influencia no tempo de uso de máscaras não profissionais utilizadas na pandemia da Covid-19? E para testar a relação entre ganho de massa pela máscara, tempo de uso das máscaras e alterações na umidade relativa do ar, mesmo com limitações metodológicas impostas pelo isolamento social, em caráter preliminar e como prova de conceito, desenvolveu-se o experimento apresentado abaixo.

Utilizou-se dois modelos de máscaras não profissionais, de tecido, compradas no comércio da cidade de Barreiras, situada no Oeste da Bahia. Uma delas era composta por $100 \%$ algodão, da cor branca e a outra composta por $90 \%$ algodão com $10 \%$ elastano, da cor preta e apresentavam dupla camada. Ao total foram utilizadas 16 máscaras, 8 brancas e 8 pretas, do mesmo modelo, compradas no mesmo estabelecimento e no mesmo dia. 
Os experimentos foram realizados em duplicata, utilizando-se a média dos dados obtidos, e foram realizados em diferentes condições ambientais, em um ambiente externo (com aproximadamente $30 \%$ de UR do ar) e ventilado e em outros ambientes fechados, simulados, sem circulação de ar e com diferentes níveis de UR do ar (50, 70 e 90\%), que foram aferidos em um higrômetro digital.

Procedeu-se à pesagem das máscaras em balança analítica de precisão ao início dos experimentos e a partir daí a cada 15 minutos de uso durante 3 a 5 horas, sendo que a máscara foi utilizada como recomendado pela Anvisa de forma a cobrir o nariz e boca do autor da pesquisa, que adentrou aos ambientes citados acima.

Em relação aos aspectos éticos, é importante ressaltar que tais experimentos não envolveram a participação de outras pessoas, além de um dos próprios autores, que se encontrava em silêncio e repouso durante o desenvolvimento de todos os testes e no laboratório da Universidade Federal do Oeste da Bahia, em ambientes simulados.

Pressupondo-se que os aumentos de peso das máscaras se devam ao acúmulo de água e outras partículas, e tendo os patamares alcançados após 3 horas de uso no ambiente externo como limite para uso, conforme recomenda as diretrizes da Agência Nacional de Vigilância Sanitária (2020), tentou-se averiguar se o tempo para atingir esses patamares era reduzido nos ambientes mais úmidos.

O programa Microsoft Excel foi utilizado para elaborar os gráficos de linha a partir da coleta de dados, permitindo a compreensão da relação entre o tempo de uso das máscaras e o ganho de massa das mesmas, em diferentes condições de UR do ar.

\section{RESULTADOS}

As máscaras testadas aparentemente retiveram umidade de formas distintas, sendo importante perceber que, em ambos os casos, os valores observados sugerem que 0 acúmulo de massa foi bastante expressivo em um intervalo de tempo de apenas 15 minutos (Figura 1). Os valores atingidos de massa com as máscaras $100 \%$ de algodão em 3 horas de uso no ambiente aberto com UR do ar de 30\% foram atingidos em 15 minutos no ambiente fechado com UR de 50\%, e foram extrapolados em 15 minutos em 3 vezes nos ambientes com UR de $70 \%$ e em 4 vezes nos com UR de $90 \%$. Em relação as máscaras de $90 \%$ algodão e $10 \%$ de elastano os valores atingidos de massa em 3 horas de uso no ambiente aberto com UR do ar de 30\% foram atingidos também em 3 horas de uso no ambiente fechado com UR de $50 \%$, e foram extrapolados em apenas 15 minutos 
em 0,02 gramas no ambiente com UR de 70\%, e em 3 vezes no ambiente com UR de 90\%. Adotando como referência os patamares de massa atingidos após $3 \mathrm{~h}$ de uso, que é o tempo de uso das máscaras não profissionais recomendado pela Anvisa, nossos experimentos indicaram que o tempo de eficácia de uma máscara não profissional pode ser menor, chegando a menos de 15 minutos, dependendo apenas das condições de UR do ar ambiental (Figura 1).

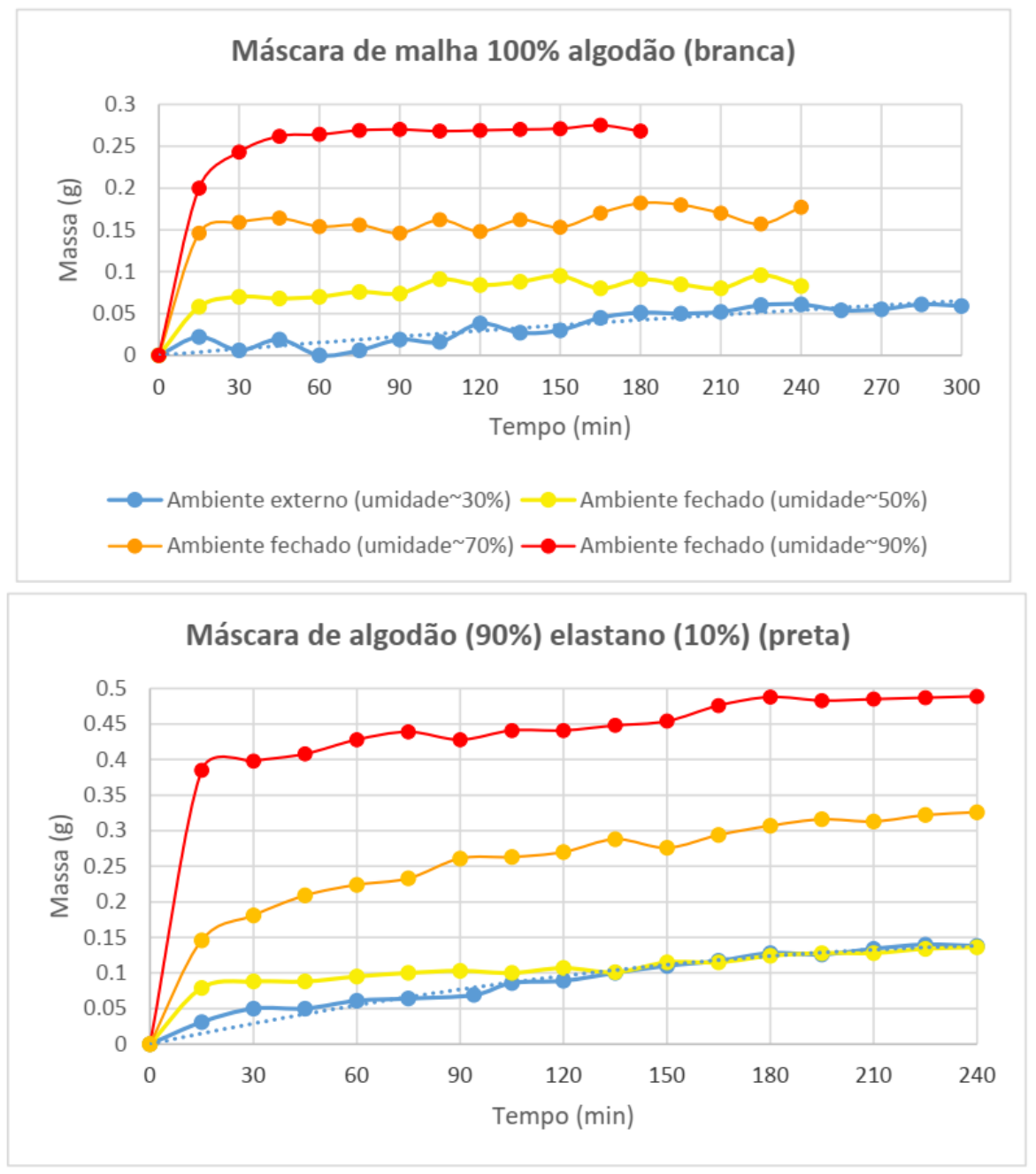

Figura 1. Aumento de massa (gramas) em função do tempo de uso de máscaras não profissionais em diferentes condições ambientais.

\section{DISCUSSÁO}

Diante do cenário desafiador da pandemia para os sistemas de saúde e governos, com destaque ao aumento do número de casos da Covid-19 na Europa e Estados Unidos, conhecido por segunda onda pandêmica, o uso de máscaras faciais não profissionais é uma intervenção não farmacológica que pode prevenir a transmissão da Covid-19 por 
reduzir significativamente a transmissão aérea de gotículas e aerossóis produzidos durante a tosse, espirro e respiração, conforme apontam recentes publicações científicas de Ngonghala e colaboradores (2020); Feng e colaboradores (2020); Rodriguez-Palacios e colaboradores 2020 e O'kelly e colaboradores (2020), sendo recomendado que as pessoas utilizem coberturas faciais com espaços minimizados em seus rostos, a fim de maximizar a eficácia da máscara (FENG, MARCHAL, 2020; WORLD HEALTH ORGANIZATION, 2020e).

A recomendação para o uso de máscaras não profissionais por pessoas infectadas assintomáticas parece ser útil, especialmente em locais onde a cobertura da testagem é baixa, a exemplo do Brasil. Neste contexto, o uso das máscaras pode reduzir a transmissão do coronavírus em comunidades onde há indivíduos assintomáticos que não receberam diagnóstico, e continuam a se interagir com outras pessoas, uma vez que pacientes com COVID-19 assintomáticos podem transmitir o vírus por muitos dias (KLOMPAS et al., 2020).

Publicações científicas comprovaram que estados norte-americanos onde o uso de máscaras faciais em público foi obrigatório tiveram uma maior taxa de declínio nas taxas de crescimento médio diário de casos de Covid-19 em comparação aos estados sem obrigatoriedade do uso das máscaras (LYU, WEHBY, 2020). Em outro estudo também norte-americano compararam uma variedade de tipos de máscara comumente disponíveis, e observaram que alguns tipos de máscara se aproximam ao desempenho de máscaras cirúrgicas padrão, em relação à redução da transmissão de gotículas respiratórias durante a conversação (FISCHER et al., 2020). Mesmo com evidências científicas, determinar a eficácia da máscara não profissional é um assunto complexo que ainda é um campo ativo de pesquisa como demonstra a literatura nos artigos de Fischer e colaboradores (2020) e Lima e colaboradores (2020), principalmente em se tratando de uma virose cujas vias de infecção ainda estão em discussão, sendo que a efetividade do uso das máscaras não profissionais está relacionada ao ajuste e uso correto das máscaras, além das variáveis ambientais.

No sentido de verificar a influência da UR do ar no tempo de uso das máscaras não profissionais desenvolvemos esta investigação, cujos resultados mesmo que com experimentos preliminares, apontaram que a UR do ar influencia no tempo necessário para a umidificação das máscaras não profissionais. Observamos que quanto maior a UR do ar, menor o tempo necessário para ganho de massa da máscara, inferindo-se que o ganho de massa advém da umidificação da máscara, então menor é o tempo necessário 
para a umidificação da máscara não profissional e consequentemente perda da efetividade de filtração do ar. Este fato aponta inegavelmente a necessidade de maior discussão dos órgãos de saúde sobre o tempo recomendado de 3 horas de uso das máscaras não profissionais, considerando-se as condições de UR do ar de algumas regiões do Sul, Sudeste, Norte e litoral do Nordeste do Brasil, que são áreas úmidas na maior parte do ano.

A UR do ar alta propicia um rápido acúmulo de partículas exaladas da respiração nos ambientes, principalmente se forem ambientes fechados e sem ventilação, como academias e algumas residências, ou qualquer outro ambiente fechado. A alta UR aumentará o tamanho das partículas exaladas da respiração $\left(\mathrm{CO}^{2}\right)$; mesmo em uso de máscara; e ocorrerá o efeito de crescimento higroscópico, que aumenta as frações de deposição das partículas no ambiente, nas superfícies e pessoas conforme relata Feng e colaboradores (2020), ou nas próprias máscaras, umidificando-as em períodos de tempos mais curtos quando comparados a ambientes com UR do ar menor. Então é justificável a relação observada em nosso experimento, a umidade ambiental favoreceu o ganho de massa das máscaras e sua umidificação, tornando sua eficiência de filtração comprometida.

Ainda é difícil discriminar o quanto as variações obtidas no experimento se devem apenas à respiração, transporte de umidade a partir do corpo e permeabilidade ao vapor dos diferentes tecidos, entre outros fatores, sendo necessária a realização de testes adicionais. Entretanto, os resultados obtidos nesta pesquisa se adicionados ao fato da conversação entre as pessoas, que é tão comum quando ocorre o encontro entre duas pessoas ou mais, ou até mesmo no ambiente familiar; e a realização de atividade física, como corrida, atividades em academias, percebe-se que os riscos são ampliados, especialmente em se tratando de regiões com UR do ar alta.

Um indivíduo infectado pode liberar aerossóis e gotículas contendo SARS-CoV-2 por tosse e espirro segundo Feng e colaboradores (2020) e World Health Organization (2020c), e ainda pela respiração conforme apresenta Wang e Du (2020) e Van Doremalen e colaboradores (2020) quando não utilizar máscaras, ou quando a máscara apresentar sua efetividade de filtração comprometida. Neste cenário um dos motivos que pode alterar a efetividade de filtração das máscaras não profissionais é a alta UR do ar, que pode umidificar a máscara rapidamente, sendo que nossos experimentos nos permitem inferir que ambientes com alta UR do ar, umidificam as máscaras mais rapidamente e as torna comprometidas na filtração. Estudos recentes de Pollitt e colaboradores (2020) 
demonstram que as gotículas (> diâmetro de $10 \mu \mathrm{m}$ de diâmetro) embora possam persistir no ar por vários minutos, e se depositarem no ambiente conforme Van Doremalen e colaboradores (2020), os aerossóis (< $10 \mu \mathrm{m}$ de diâmetro) não se assentam rapidamente e podem persistir no ar por períodos mais longos ( minutos a horas) (FERNSTROM, GOLDBLATT, 2013). Os aerossóis podem permanecer infecciosos no ar e em superfícies por horas, com apenas uma ligeira redução em sua infecciosidade, sendo que com base na observação desse estudo, afirma-se que os aerossóis podem ser transportados no ar a mais de 1,83 m (VAN DOREMALEN et al., 2020).

Outro estudo publicado por Wang e colaboradores (2005) também aponta que sob maior UR do ar, as gotículas exaladas evaporam lentamente e as maiores caem mais rápido, mas os aerossóis, permanecem no ar e podem ser disseminados, contaminando as pessoas, mesmo que distantes. Este pode ser um dos fatores mais importantes que influenciam a transmissão da SARS no ar e que deve ser levado em consideração em todos os ambientes, mas principalmente nos ambientes úmidos e sem ventilação aérea, que podem reter os aerossóis por mais tempo, e podem diminuir o tempo de uso das máscaras não profissionais, como ficou demonstrado em nossa investigação, estes achados podem contribuir para o entendimento da facilidade de transmissão da Covid-19.

Ressalta-se a urgência e a necessidade de novos estudos visto que a pandemia apresenta números crescentes novamente em alguns países e demanda que as decisões de prevenção sejam tomadas com base em evidências científicas. Porém, enquanto novas pesquisas são realizadas envolvendo a prevenção da transmissão da Covid-19, sugere-se que seja continuada a indicação do uso de máscaras não profissional pela população, principalmente com alta cobertura (mais de uma camada) conforme preconiza a Anvisa, devido à sua capacidade de maior proteção na absorção de partículas nanométricas semelhantes à estrutura da SARS-CoV-2 (LIMA et al., 2020; NGONGHALA et al., 2020; RODRIGUEZ-PALACIOS et al., 2020; O'KELLY et al., 2020). Entretanto sugere-se que seja melhor discutido pelos órgãos de saúde o tempo recomendado de uso das máscaras não profissionais (3 horas) em casos de ambientes com UR do ar alta.

\section{CONCLUSÖES}

Em face ao enfrentamento da pandemia da Covid-19, a utilização das intervenções não farmacológicas incluindo o uso de máscaras não profissionais permitiu a criação de barreiras físicas, diminuindo a exposição e o risco de infecção para a população em geral. 
Entretanto, demonstramos que fatores ambientais como a UR do ar alta podem diminuir o tempo recomendado pela Anvisa de uso das máscaras não profissionais. Sugerimos então maiores discussões das autoridades e órgãos de saúde à cerca desta questão, despontando um olhar mais crítico, de alerta ao tempo de uso das máscaras não profissionais à população de algumas regiões do Sul, Sudeste, Norte e litoral do Nordeste, que estão expostas a ambientes com UR do ar alta, como pessoas frequentadoras de academias, moradores de residências fechadas e sem ventilação, casas litorâneas, enfim, pessoas expostas a quaisquer ambientes fechados localizados em regiões de UR do ar alta. Nestes ambientes as máscaras não profissionais podem se umidificar rapidamente e podem apresentar comprometida a efetividade de filtração das partículas do SARS-CoV2, perdendo seu papel preventivo no ciclo de transmissão da Covid-19.

\section{REFERÉNCIAS}

Agência Nacional de Vigilância Sanitária (ANVISA) (2020). ORIENTAÇÕES GERAIS Máscaras faciais de uso não profissional. [Internet] Brasília, 03 de abril de 2020, 11p. Disponível em: <http://portal.anvisa.gov.br/documents/219201/4340788/NT+M\%C3\%A1scaras.pdf>, Acesso em: 03/11/2020.

BOCCIA, S.; RICCIARD, W.; IOANNIDIS, J.P.A. What other countries can learn from Italy during the COVID-19 pandemic. JAMA. v.180, n.7, p.927-8, 2020. Disponível em: <http://dx.doi.org/10.1001/jamainternmed.2020.1447>, Acesso em: 28/10/2020

BRASIL, 2020. LEI № 14.019, DE 2 DE JULHO DE 2020. Altera a Lei o 13.979, de 6 de fevereiro de 2020. Diário Oficial da União [Internet] Edição: 126, Seção: 1, 03/07/2020, Página: 2, Disponível em: <https://www.in.gov.br/en/web/dou/-/lei-n-14.019-de-2-de-julhode-2020-264918074>Acesso em: 10/10/2020.

BUONANNO G, MORAWSKA L, STABILE L. Quantitative assessment of the risk of airborne transmission of SARS-CoV-2 infection: perspective and retrospective applications. Environ Int. n.145, 106112, 2020. Disponível em: <https://doi.org/10.1016/j.envint.2020.106112> Acesso em: 08/10/2020.

CAI J, SUN W, HUANG J, GAMBER M, WU J, HE G. Indirect virus transmission in cluster of COVID-19 cases, Wenzhou, China, 2020. Emerg Infect Dis. v.26, n.6, p.1343-45, 2020. Disponível em: <https://doi.org/10.3201/eid2606.200412> Acesso em: 02/09/2020.

CANDIDO DS, WATTS A, ABADE L, KRAEMER MUG, PYBUS OG, CRODA, J et al. Routes for COVID-19 importation in Brazil. J Travel Med. v.27, n.3, p.1-3, 2020. Disponível em: <https://doi.org/10.1093/itm/taaa042> Acesso em: 10/09/2020.

Centers for Disease Control and Prevention. Recommendation regarding the use of cloth face coverings, especially in areas of significant community-based transmission [Internet]. Atlanta (GA): CDC; [Acesso em 02/09/2020]. Disponível em: < https://www.cdc .gov/coronavirus/2019-ncov/ prevent-getting-sick/cloth-facecover.html > Acesso em: 20/11/2020. 
Coronaviridae Study Group of the International Committee on Taxonomy of Viruses. The species Severe acute respiratory syndrome-related coronavirus: classifying 2019-nCoV and naming it SARS-CoV-2. Nat. Microbiol. v.5, n.4, p.536-544, 2020. Disponível em: <doi.org/10.1038/s41564-020-0695-z (2020)> Acesso em: 08/11/2020.

COVID-19 CORONAVIRUS PANDEMIC. 2020. [Internet]. Disponível em: <https://www.worldometers.info/coronavirus/> Acesso em: 28/11/2020.

FENG Y, MARCHAL T, SPERRY T, YI H. Influence of wind and relative humidity on the social distancing effectiveness to prevent COVID-19 airborne transmission: A numerical study. J Aerosol Sci. v.147, p.105585, 2020. Disponível em: <https://doi.org/10.1016/j.jaerosci.2020.105585> Acesso em: 07/09/2020.

FERNSTROM A, GOLDBLATT M. AEROBIOLOGY and its role in the transmission of infectious diseases. J Pathog., Article ID 493960, 13 pages, 2013. Disponível em: https://www.hindawi.com/journals/jpath/2013/493960/,

Disponível

em:

<http://dx.doi.org/10.1155/2013/493960 > Acesso em: 10/09/2020.

FISCHER EP, FISCHER MC, GRASS D, HENRION I, WARREN WS, WESTMAN E. LOWcost measurement of facemask efficacy for filtering expelled droplets during speech. Sci. Adv. v.6, n.36, p.eabd3083, 2020. Disponível em: <https://dx.doi.org/10.1126\%2Fsciadv.abd3083> Acesso em: 03/09/2020.

GUAN W, NI Z, HU Y, LIANG W, OU C, HE J, et al. Clinical characteristics of coronavirus disease 2019 in China. N. Engl. J Med. v.382, n.18, p.1708-1720, 2020. Disponível em: < Doi: 10.1056/NEJMoa2002032> Acesso em: 08/10/2020.

KLOMPAS M, MORRIS CA, SINCLAIR J, PEARSON M, SHENOY ES. Universal Masking in Hospitals in the Covid-19 Era. N. Engl. J. Med. v.382, n.21, 2020. Disponível em <https://www.nejm.org/doi/full/10.1056/nejmp2006372, doi: 10.1056/NEJMp2006372 > Acesso em: 10/11/2020.

KUCHARSKI AJ, RUSSEL TW, DIAMOND C, LIU Y, EDMUNDS J, FUNK S, et al. Early dynamics of transmission and control of COVID-19: a mathematical modelling study. Lancet Infect Dis. v. 20, n.5, p. 553-8, 2020. Disponível em: $<$ https://doi.org/10.1016/S1473-> Acesso em: 03/09/2020.

LAI CC, WANG CY, WANG YH, HSUEH SC, KO WC, HSUEH PR. Global epidemiology of coronavirus disease 2019: disease incidence, daily cumulative index, mortality, and their association with country healthcare resources and economic status. Int. J. Antimicrob Agents.v.55, n.4, p.105946, 2020. Disponível em: <http://dx.doi.org/10.1016/ > Acesso em: 01/09/2020.

LI Y, QIAN H, HANG J, CHEN X, HONG L, LIANG P, et al. Evidence for probable aerosol transmission of SARS-CoV-2 in a poorly ventilated restaurant. MedRxiv pre-print. 2020. Disponível em: <https://www.medrxiv.org/content/10.1101/2020.04.16.20067728v1, doi: https://doi.org/10.1101/2020.04.16.20067728.t> Acesso em: 03/09/2020

LIMA MMS, CAVALCANTE FML, MACÊDO TS, GALINDO-NETO NM, CAETANO JA, BARROS LM. Cloth face masks to prevent Covid-19 and other respiratory infections. Rev Lat Am Enfermagem.v.28, p. e3353, 2020. Disponível em: <www.eerp.usp.br/rlae, doi: http://dx.doi.org/10.1590/1518-8345.4537.3353> Acesso em: 08/11/2020. 
LYU BW, WEHBY GL. Community Use Of Face Masks And COVID-19: Evidence From A Natural Experiment Of State Mandates In The US. Health Aff. v.39, n.8, p.1419-25, 2020. Disponível em: < https://doi.org/10.1377/hlthaff.2020.00818> Acesso em: 30/10/2020.

LU R, ZHAO X, LI J, NIU P, YANG B, WU H, et al. Genomic characterisation and epidemiology of 2019 novel coronavirus: implications for virus origins and receptor binding. Lancet. v. 395, n.10224, p.565-74, 2020. Disponível em: <https://doi.org/10.1016/S01406736(20)30251-8> Acesso em: 30/09/2020

MORAWSKA L, MILTON DK. It is time to address airborne transmission of COVID-19. Clin Infect Dis. ciaa 939, 2020. Disponível em: <https://doi.org/10.1093/cid/ciaa939> Acesso em: 23/09/2020.

MOUSAVIZADEH L, GHASEMI S. Genotype and phenotype of COVID-19: Their roles in pathogenesis. J Microbiol Immunol Infect. Article in press. 2020. Disponível em: <https://doi.org/10.1016/j.jmii.2020.03.022> Acesso em: 01/11/2020.

NGONGHALA CN, IBOI E, EIKENBERRY S, SCOTCH M., MACINTYRE CR, BONDS MH, et al. Mathematical assessment of the impact of non-pharmaceutical interventions on curtailing the 2019 novel Coronavirus. Math Biosci. v.325, n.1, p.108364, 2020. Disponível em: <https://doi.org/10.1016/j.mbs.2020.108364> Acesso em: 07/09/2020.

O'KELLY E, PIROG S, WARD J, et al. Ability of fabric face mask materials to filter ultrafine particles at coughing velocity. BMJ Open. v.10, p.e 039424, 2020. Disponível em: $<$ https://www.ncbi.nlm.nih.gov/pmc/articles/PMC7509966/, https://dx.doi.org/10.1136\%2Fbmjopen-2020-039424> Acesso em: 20/10/2020

POLLITT KJG, PECCIA J, KO AI, KAMINSKI N, CRUZ CSD, NEBERT DW, et al. COVID19 vulnerability: the potential impact of genetic susceptibility and airborne transmission. Hum Genomics. v.14, n.17, 2020. Disponível em: <https://doi.org/10.1186/s40246-02000267-3 > Acesso em: 25/10/2020.

RODRIGUEZ-PALACIOS A, COMINELLI F, BASSON AR, PIZARRO TT AND ILIC S. Textile Masks and Surface Covers-A Spray Simulation Method and a "Universal Droplet Reduction Model” Against Respiratory Pandemics. Front. Med. v.7, n.260, 2020.

Disponível em: < https://dx.doi.org/10.1126\%2Fsciadv.abd3083> Acesso em: 15/11/2020.

SOUZA WM, BUSS LF, CANDIDO DS, CARRERA JP, LI S, ZAREBSKI AE, et al. Epidemiological and clinical characteristics of the COVID-19 epidemic in Brazil. Nat Hum Behav. v.4, p.856-65, 2020. Disponível em: <doi://doi.org/10.1038/s4156-020-0928-4 > Acesso em: 10/11/2020

VAN DOREMALEN N, BUSHMAKER T, MORRIS DH, HOLBROOK MG, GAMBLE A, WILLIAMSON BN et al. Aerosol and surface stability of SARS-CoV-2 as compared with SARS-CoV-1. N. Engl. J. Med. v.382, p.1564-1567, 2020. Disponível em: <https://doi.org/10.1056/NEJMc2004973 > Acesso em: 20/11/020.

WANG B, ZHANG A, SUN JL, LIU H, HU J, XU LX. Study of SARS Transmission Via Liquid Droplets in Air. J Biomech Eng. v.127, n.1, p. 32-8, 2005. Disponível em: < doi: 10.1115/1.1835350 > Acesso em: 05/10/2020. 
WANG J, DU G. COVID-19 may transmit through aerosol. Ir J Med Sci. v.189, p.1143-44, 2020. Disponível em: <https://doi.org/10.1007/s11845-020-02218-2 > Acesso em: 03/10/2020.

World Health Organization. Report of the WHO-China Joint Mission on Coronavirus Disease 2019 (COVID-19). [Internet]. 2020a. Disponível em: $<$ https://www.who.int/docs/default-source/coronaviruse/who-china-joint-mission-on-covid19-final-report.pdf $>$ Acesso em: 30/08/2020.

World Health Organization. WHO Coronavirus disease (COVID 19) Dashboard. 2020b. [Internet] [Acesso: 16/11/2020], Disponível em: < https://covid19.who.int > Acesso em: 16/11/2020.

World Health Organization. Coronavirus disease (COVID-19) pandemic. Questions and answer. Q\&As on COVID-19 and related health topics. Q\&A on coronaviruses (COVID19). What are the symptoms of Covid 19? 2020c. [Internet] Disponível em: < https://www.who.int/emergencies/diseases/novel-coronavirus-2019/question-and-answershub/q-a-detail/q-a-coronaviruses > Acesso em: 25/09/2020.

World Health Organization. Coronavirus disease (COVID-19) pandemic. Advice for the public. Protect yourself and others from COVID-19. 2020d [Internet]. Disponível em: $<$ https://www.who.int/emergencies/diseases/novel-coronavirus-2019/advice-for-public > Acesso em: 25/09/2020.

World Health Organization. Coronavirus disease (COVID-19) advice for the public: When and how to use masks [Internet]. Geneva: World Health Organization; 2020e Disponível em: <https://www.who.int/emergencies/diseases/novel-coronavirus-2019/advice-forpublic/when-and-how-to-use-masks $>$ Acesso em: 20/09/2020. 